[[Forthcoming in Philosophical Studies - this is an uncorrected draft, so please don't quote or cite this version!]]

\title{
Science, Substance and Spatial Appearances
}

\begin{abstract}
According to a certain kind of naïve or folk understanding of physical matter, everyday 'solid' objects are composed of a homogeneous, gap-less substance, with sharply defined boundaries, which wholly fills the space they occupy. A further claim is that our perceptual experience of the environment represents or indicates that the objects around us conform to this sort of conception of physical matter. Were this further claim correct, it would mean that the way that the world appears to us in experience conflicts with the deliverances of our best current scientific theories in the following respect: perceptual experience would be intrinsically misleading concerning the structure of physical matter. I argue against this further claim. Experience in itself is not committed to, nor does it provide evidence for, any such conception of the nature of physical matter. The naïve/folk conception of matter in question cannot simply be 'read-off' from perceptual appearances.
\end{abstract}

\section{Introduction: an alleged clash}

Perhaps the single most famous statement of the clash between what science tells us about the nature of physical objects and our common-sense or folk conception of physical objects, is the introduction to Sir Arthur Eddington's 1927 Gifford Lectures ${ }^{1}$. Eddington contrasted the 'familiar', 'commonplace' table "which lies visible to my eyes and tangible to my grasp", with the 'Scientific table', which is 'nearly all empty space'. Perhaps the key difference between the commonplace conception of the table and the scientific conception is that the former, according to Eddington, is committed to the idea that everyday physical objects are composed of 'substance' which entirely fills the space it occupies, excluding other matter - whereas the scientific conception denies this.

"It makes all the difference in the world whether the paper before me is poised as it were on a swarm of flies and sustained in shuttlecock fashion by a series of tiny blows from the swarm underneath, or whether it is supported because there is substance below it, it being the intrinsic nature of substance to occupy space to the exclusion of other substance." (Eddington, 1928, 4)

\footnotetext{
${ }^{1}$ Published the following year, 1928, with the title "The Nature of the Physical World".
} 
One idea that we can take from Eddington is that our best scientific theories about the nature of physical matter are inconsistent with our folk, intuitive conception of physical matter $^{2}$. A somewhat different idea that we might take from Eddington is that our best scientific theories about the nature of physical matter clash with the deliverances of our conscious, visual experiences. For example, Eddington writes:

'...the process by which the external world of physics is transformed into a world of familiar acquaintance in human consciousness is outside the scope of physics. And so the world studied according to the methods of physics remains detached from the world familiar to consciousness...' (Eddington, 1928, 5)

We might then naturally combine these two ideas in the following way: the reason why people have an erroneous 'folk' conception of the physical world as: mostly populated by objects composed of some homogeneous substantial matter that entirely fills the space it occupies, with sharply defined edges and boundaries etc, is that our perceptual experiences present the world as populated by such objects with such properties. I.e. the source of our mistaken common-sense conception of our physical environment is that our experiences are antecedently committed to the environment being that way. And so, on this way of thinking, the surprising revelations from physics as to the micro-physical nature of matter don't just clash with our common-sense or naïve conception of the world, physics also clashes with the content or testimony of the senses ${ }^{3}$.

\footnotetext{
${ }^{2}$ Wilfrid Sellars explicitly connected his famous distinction between the 'Manifest Image' and the 'Scientific Image' with Eddington's 'two tables':

"It is worth noting that we have here a recurrence of the essential features of Eddington's 'two tables' problem - the two tables being, in our terminology, the table of the manifest image and the table of the scientific image. There the problem was to 'fit together' the manifest table with the scientific table. Here the problem is to fit together the manifest sensation with its neurophysiological counterpart. And, interestingly enough, the problem in both cases is essentially the same: how to reconcile the ultimate homogeneity of the manifest image with the ultimate non-homogeneity of the system of scientific objects." (Sellars, 1962, 35-36)

3 Of course, the idea that experience is the source of our mistaken folk-beliefs about physical matter is not required for the thesis that experience clashes with science. It could be, for example, that our folk conception of matter is innate and not derived from experience - and yet the experiential content might still clash with science.
} 
More recently, John Campbell has also written about the apparent conflict between the nature of our sensory perceptual experiences and the picture of the world provided by physical science:

'Mathematical physics gave us a firm conception of 'matter'. But it seemed to show our surroundings to be unlike anything in sensory experience... The trouble is that physics seems to push sensory experience inside the head...If mathematical physics is the whole truth about our surroundings, then the qualitative character of our sensory experience seems to have little to do with the qualitative character of our surroundings.' (Campbell \& Cassam, 2014, 2)

To be clear, Campbell is not here endorsing the idea that 'sensory experience has little to do with the qualitative nature of our surroundings'. (He ultimately wants to claim that we can have direct conscious acquaintance with the shapes and colours of everyday physical objects in our surroundings.) But he is articulating the idea that there is some kind of tension, which needs somehow to be resolved, between the nature of our sensory experience and the deliverances of physics.

I am happy to grant that our best scientific theories about the nature of physical matter may well clash with our naïve/folk beliefs (or folk concepts, expectations etc.). But the overall aim for this paper will be to establish that there is no such tension between the way that the spatial features of familiar, medium-sized objects typically appear in visual experience and our best scientific theories about the nature of the physical matter that constitutes those objects. I will say nothing about whether or not there is a conflict between the visual colour appearances of ordinary objects and our best scientific theories - the metaphysics of colour is a "whole other" difficult and contentious topic that I want to set aside entirely. 


\section{Reacting to the alleged clash}

Why does it matter whether physics clashes with the deliverances of perceptual experience? Well, once we accept that the spatial properties that we are apparently presented with in visual experience are, systematically, not in fact properties possessed by the physical objects in our environment, then it can seem hard to avoid accepting an 'indirect' model of perception according to which the spatial properties we are apparently presented with are a mere 'veil of appearances'. Or as Campbell put it in the passage quoted above, the apparently external spatial properties we are presented with in visual experience seem to get 'pushed inside our heads'.

In the case of Eddington this seems to have motivated something like a kind of 'epistemic structural realism' concerning our cognitive contact with the external, physical world ${ }^{4}$. In his Gifford Lectures, Eddington speaks of the 'shadowy' and 'purely symbolic' nature of the external world as described by physics:

"The external world of physics has thus become a world of shadows. ... It is all symbolic, and as a symbol the physicist leaves it. Then comes the alchemist Mind who transmutes the symbols. The sparsely spread nuclei of electric force become a tangible solid; their restless agitation becomes the warmth of summer; the octave of aethereal vibrations becomes a gorgeous rainbow... It is difficult to school ourselves to treat the physical world as purely symbolic. We are always relapsing and mixing with the symbols incongruous conceptions taken from the world of consciousness. Untaught by long experience we stretch a hand to grasp the shadow, instead of accepting its shadowy nature." (Eddington, 1928, 7)

Likewise in his later book - 'Philosophy of Physical Science' (1939) Eddington writes:

\footnotetext{
4 The label 'structural realism' is due originally to Maxwell (1970). Whereas an epistemic structural realist (e.g. Russell, 1927, Worrall 1989) holds that all that science can allow us to know about the (unobservable) world is its relational structure, an ontic structural realist (e.g. French \& Ladyman 2003, Esfeld 2009) holds that ultimately all there is to reality/nature is such relational structure.
} 
"What sort of thing is it that I know? The answer is structure. To be quite precise it is structure of the kind defined and investigated in the mathematical theory of groups" (Eddington, 1939, 147)

John Campbell's suggestion for avoiding the conclusion that the spatial features which we are apparently presented with in experience are features merely of the 'world of consciousness' is that we should accept that reality can be correctly described at many different 'levels'.

'But how can we resist the way in which physics pushes sensory experience inside the head? Our understanding of sensory experience could be transformed by giving due weight to the idea that reality can be described 'at many levels'. We can acknowledge that there is something fundamental about the physics of our surroundings... whilst being pluralist about our world, which can be described 'at many levels', and the [fundamental] physical is only one level of description, even if it is a particularly fundamental level of description.

...This opens the possibility that characterizing the qualitative world we encounter in experience, the colours and shapes, the beach ball on the sand, and so on, is simply a matter of saying how things are 'at a different level' than the level of description used by the physicist... The dissonance between the qualitative character of experience and the qualitative character of the world as described by physics may then be merely an artifact of our shifting from one level of description to another.' (Campbell \& Cassam, 2014, 3)

Campbell does not really go into much further detail about what exactly a 'level' of reality is supposed to be. But I think that we can draw a broad distinction between a metaphysically-heavyweight understanding and a much more lightweight or deflationary understanding. According to the more metaphysically heavyweight thesis, reality itself is structured into different levels or domains, which are then related according to some interesting, substantive metaphysical relation - such as 'grounding' or 'ontological dependence', or perhaps just supervenience with either metaphysical or merely 
nomological necessity. (See e.g. Wilson 2010, 2011, 2015, Baysan \& Wilson 2017, Gillet 2002,2003 , Pereboom 2002.) On the assumption that there is a most fundamental level e.g. the level of fundamental physical particles and forces - the other levels to reality then may be grounded or determined or metaphysically explained by the most fundamental level. But, on the sort of non-reductive, or even emergentist understanding I am currently sketching, these other levels or domains to reality are conceived of as in some important sense additional to and distinct from the fundamental stuff - i.e. the items and features in these extra levels are not conceived as 'reducing to' or being merely 'nothing over and above' the items and features in the most fundamental level. (This more metaphysically heavyweight understanding might be suggested by Campbell's talk of fundamentality and of being 'pluralist about our world'.)

In contrast, the lightweight or deflationary notion is just the uncontroversial claim that reality can be described at many different scales and using many different vocabularies or representational systems, where this carries no commitment to the idea that reality itself is structured into levels or to the idea that everyday items, like tables and chairs, are somehow something 'over and above' the fundamental particles and forces which constitute them. (This more lightweight understanding might be suggested by Campbell's use of the phrase 'level of description'.)

If we understand Campbell's suggestion in terms of the more metaphysically heavyweight notion of 'levels', then the idea would be to accept that sensory experience does not present us with the cloud of quarks and leptons that physics tells us the table is composed of, nor their spatial arrangement, but to insist that our experience does nevertheless acquaint us with some other, higher-level features of reality. These features that can be presented in consciousness would be a different 'level' to reality macroscopic shape and colour, and perhaps also the macroscopic objects themselves, would be understood as genuinely distinct, extra portions of reality, over-and-above the specific arrangement of the cloud of micro-particles, even if they supervene on the arrangement of the cloud of micro- particles. We could then accept that physics and experience 'say' different things, and yet avoid the conclusion that the spatial features we 
are apparently presented with in experience are merely inner features/artifacts of consciousness, by allowing our experiences to be revelatory of a different level of external reality, distinct from that which is described in the language of, say, particle physics.

Now, much more could be said, of course, about how this more heavyweight conception of 'levels' to reality should be fleshed out and made more precise. But for present purposes we can set these issues aside, since the aim of this paper will be to argue against the idea that the spatial appearances of the everyday objects that we are presented with in visual experience are in any tension with the deliverances of contemporary physics in the first place, at least in the respect that Eddington was concerned about. The spatial appearances of everyday objects do not provide a motivation to adopt some kind of epistemic structural realism, nor to endorse some metaphysically heavyweight notion that there are different levels to reality - though of course there may well be all sorts of other good reasons to endorse either of these philosophical positions.

I will provide two different lines of thought in support of the claim that there is no clash between everyday visual spatial appearances and our best physical theories. The first line of thought will be couched in terms of the widespread, orthodox idea that our visual experiences have representational content that the external world is some way. This first line of thought can be understood as appealing only to the non-contentious, lightweight idea that the external world can be described and represented at many different scales and with different degrees of precision and determinacy.

The second line of thought will be couched in terms of visual appearances and what they might reasonably indicate to be the case. This second line of thought thus does not assume anything about the metaphysics of experience - and in particular it does not appeal to the (potentially controversial) assumption that visual experience is representational. 


\section{Representational indeterminacy}

The first point to make is that within an orthodox sort of representational framework for perceptual experience, it is commonly assumed that spatial properties are represented only up to a certain degree of determinacy ${ }^{5}$. A normal successful perceptual experience accurately represents that an object has a general or determinable kind of shape, size and location without representing any perfectly specific or determinate spatial properties. So my experience might represent you as being about $6 \mathrm{ft}$ tall without representing that you have any more specific or determinate height in particular. Likewise, my visual experience represents that a billiard ball has a shape that is more or less smoothly spherical-i.e. up to a certain degree of determinacy - without representing that the ball is perfectly smooth or perfectly spherical right down to the scale of molecules or atoms.

Just to give one example of a representational theorist explicitly stating the determinable nature of perceptual content, consider Peacocke's (1992) influential account of the 'scenario content' that he claims is possessed by perceptual experience.

'...in giving the content we should consider a set of ways of filling out the space...

Greater acuity corresponds to restriction on the set of ways of filling out the space whose instantiation is consistent with the correctness of the representational content.' (Peacocke, 1992, 107)

In other words: when I see you and your height there is a whole range of different specific heights around $6 \mathrm{ft}$ tall that you could be consistent with my experience being veridical. When I see the billiard ball, there is a whole range of roughly smooth and spherical shapes that the ball could be consistent with the experience being veridical. Greater acuity of vision, and perhaps also attention, can narrow this range down somewhat as your height, or the ball's shape, is represented with greater determinacy, but this spatial content is still nowhere near specific enough to capture microscopic details.

\footnotetext{
${ }^{5}$ See Nanay $(2010,2018)$ and Cutter (forthcoming) for recent discussions of the indeterminacy of perceptual content.
} 
And indeed, it is often claimed that an advantage of a representational account of experience is that by appealing to the indeterminacy of representational content it can explain various kinds of phenomenological indeterminacy - such as blurriness of vision or 'speckled hen' cases $^{6}$. Moreover, there are a number of empirical results from cognitive science which have been interpreted as showing that shifts in attention can measurably affect the determinacy with which environmental properties are represented. See: Gobell \& Carrasco (2005), Yeshurun \& Carrasco (2008), Carrasco (2011) for the empirical work; see Stazicker (2011), Nanay (2010), Ganson \& Bronner (2013) for philosophical interpretation of these results in terms of determinacy of representational content.

So now here is a comparison: suppose you are looking at a long sandy beach that is a few miles distant but in perfectly plain view - one sees an undifferentiated expanse of a certain shape and a certain whitish-yellow colour. Is there any temptation here to suggest that because you cannot make out all the trillions of individual grains of sand, one's experience must therefore be an illusion or projection? No, I take it. That is just how we expect trillions of grains of sand look from a goodly distance away. It would be quite implausible to suppose that your visual experience in this situation positively represents that the beach is a perfectly homogenous mass of yellow substance with no gaps - and thus should be counted as a visual illusion or misrepresentation. It is much more plausible to suppose that your experience is simply silent about the possible fine-grained structure of the beach. There is no content or commitment in the experience about the fine-grained structure of the beach being any specific way - except, of course, the implicit commitment that this fine-grained structure, whatever it is, be consistent with the much more coarse-grained, determinable spatial structure that is represented. Given the assumption that such an experience does represent something about the spatial nature/structure of the beach, it presumably represents only its general, large-scale shape, size and location. That the human visual system has natural limits to its resolution, so that the fine detail of an object's outline or location can never be represented with perfect determinacy, is hardly a reason to count all visual experiences as illusions.

\footnotetext{
${ }^{6}$ See, for example, Nanay (2018).
} 
Likewise then, my suggestion is that we need not be panicked by the surprising or unfamiliar descriptions of matter at the microscopic scale that occur in physics textbooks, into accepting that our sensory experiences of the table's macroscopic shape are mere inner projections caused by shadowy, noumenal external items. Nor does the nature of phenomenal perceptual appearances provide any obvious theoretical pressure to accept that there are, in the metaphysically-heavyweight sense, many different levels to reality and that the level revealed by sensory experience is distinct from the level described by physics. (Of course, to repeat: this leaves open that there may well be lots of other good reasons to accept a 'layered' metaphysics.) Rather, we can simply maintain that the swarm of particles and their spatial arrangement that physics tells us composes the familiar table is just what we are gaining conscious awareness of in perceptual experience. Why should our inability to discriminate individual atoms or electrons that compose the table lead us to conclude that we are experiencing anything other than the vast cloud of those very atoms or electrons?

Having drawn the analogy with seeing a distant beach, let me straight away make explicit a couple of obvious respects in which the analogy is, of course, imperfect. Firstly, the space between the nucleus of an atom and the surrounding electron 'cloud' is, proportionally speaking, many orders of magnitude larger than the pockets of space in between the grains of sand that make up a beach - though in absolute terms the atomic radius is measured in trillionths of a meter ${ }^{7}$. Secondly, fundamental particles should certainly not, of course, be thought of as being just like incredibly tiny grains of sand, nor as incredibly tiny billiard-ball-shaped lumps of substance. The nature of matter at this fundamental scale is so utterly different to things at our familiar macroscopic scale that it can be hard (for many of us at least) to get any kind of satisfying or intuitive grip on it.

\footnotetext{
7 The radii of the atoms of different elements vary from around 30-300 picometers. The distance from the nucleus to the surrounding electrons is thus typically over 10,000 times larger than the size of the nucleus itself, which is 0.01-0.001 picometres in radius. Though of course, one of the bizarre, counter-intuitive features of matter at this scale is that the orbiting electrons don't have sharply defined locations, but rather a probability distribution of possible locations.
} 
Nevertheless, despite these disanalogies, I think the moral of the comparison remains the spatial properties and features of fundamental particles described by physics occur at a scale that is vastly smaller than anything that could be discriminated by the human eye. And there is just no obvious reason to think that the content of human visual experience takes any stand about the nature of physical matter at this invisibly tiny scale. If the point, emphasised by Eddington, that physical matter turns out to be 'nearly all empty space', continues to strike one as a significant disanalogy with the sand constituting the beach, then consider instead a slightly different comparison. Suppose you see an object moving in the sky that is so far distant that it is only just visible - it appears simply as a speck, nothing of its shape or internal structure can be discerned. Now suppose when you get much closer to the item that it turns out to be a thin wire frame, in the shape, say, of a cube. The object then turns out to be 'nearly all empty space'. But again - that is surely no reason to think that the initial experience of it, when it appeared as just a speck on the horizon, was illusory or positively represented that the object is gapless and substantial. Rather, the initial experience was simply silent about the item's fine-grained spatial structure.

Someone might worry that there might be an important difference between seeing an object in the far distance and seeing an object right in front of one - i.e. between seeing something in sub-optimal viewing conditions vs. optimal/normal viewing conditions. Just because an experience of a sandy beach, or a wire frame cube, in the far distance is 'silent' about the fine-grained spatial structure of these items, does that mean that an experience of a table right before our eyes (in optimal lighting etc.) is likewise silent about fine-grained spatial structure? Well, it should certainly be admitted that visual experiences might represent spatial features with different degrees of determinacy and precision depending on the circumstances of viewing - e.g. from a distance vs. close-up. But still, I think it is clear that this worry is misplaced. The crucial point is that it is quite implausible that there is some viewpoint (and some viewing conditions) we can occupy towards an everyday object, such as a table, where we expect that our visual experience should be perfectly or entirely revelatory of all its fine-grained spatial structure and detail. As I look at the table that my laptop is currently sat upon, only 18 inches or so 
from my eyes, under excellent bright lighting, my visual experience is presumably as close to being had under optimal viewing conditions as one could hope for. I naturally treat my experience of the table's shape under these conditions as totally normal and nonillusory. Yet I also assume that if I were to stick my face right up against the surface of the table and squint a bit that I would presumably then be able to visually discriminate various tiny bumps and pits and scratches etc. that I cannot currently see. And of course if I were to get out a magnifying glass I would expect to see yet further spatial details that I cannot currently see. This does not threaten to convict my current, normal visual experience of the table's shape and spatial structure as illusory since even in this near optimal circumstance of seeing an everyday object right before me in excellent light I still naturally expect that there is yet more detail to the spatial structure of the table than is revealed in this experience. Putting this in representational terms: we do not expect the spatial content of our everyday visual experiences, even in optimal conditions, to be perfectly precise, detailed or determinate.

Now I hesitate to attribute the following error to Eddington - who nowhere discusses the representational content of experience and who was writing long before this became an orthodox notion in philosophy - but a potential confusion that is relevant here would be: mistaking the lack of a representation for a representation of a lack. There is a crucial difference between an experience positively representing that the object has a simple/homogeneous/gap-less structure at the microscopic level compared with the experience just not 'saying' anything about the fine-grained microscopic structure of an object. When we think about, say, the visual phenomenology of seeing a solid table before us, there may be some initial temptation to think that the experience itself embodies a commitment to the table being composed of a homogenous, gap- less, wholly-space-filling substance right down to the most microscopic scales. But reflecting on the example of the distant beach should, I suggest, incline us to the view that the visual phenomenology, the experience in itself, is just silent or neutral about the structure of the matter at very fine-grained scales. 
To be clear: I am not claiming that it would be contradictory or incoherent to hold that our conscious perceptual experience possesses content that everyday objects are composed of a substance that is homogenous and gap-less, with sharp boundaries right down to microscopic - i.e. invisible - scales. Nor am I claiming that the manifest phenomenology of our visual experience definitively rules out such a view about the content of experience. Indeed it may be that in some special circumstances our visual experience can represent an external item as being, say, perfectly spherical. Rather, I have simply pointed out that according to standard representational theories perceptual experiences do not generally or systematically possess contents with this sort of spatial determinacy ${ }^{8}$. And when we reflect on the nature of our visual phenomenology when we see everyday physical objects, we come to realize that it provides no positive support for thinking that it possesses such content.

\section{An anecdote and its moral}

So now to the second line of thought - which is partly an excuse to re-tell a favorite old philosophy anecdote ${ }^{9}$. But I also want to shift from discussing the (presumed) representational content of experience, to considering what perceptual appearances indicate or provide evidence for.

Once upon a time, a student of Wittgenstein (reportedly Anscombe ${ }^{10}$ ) is supposed to have remarked: "it doesn't look like the earth is rotating". The student thought she was stating something obvious and non-contentious. Clever old Wittgenstein, however, is supposed to have asked in response: "Well, how should a rotating earth look?" - his point being that as the earth does in fact rotate, surely the way that things look is the way that a rotating earth, in fact, looks.

\footnotetext{
${ }^{8}$ And after all, what would be the evolutionary purpose of a visual system ascribing spatial properties to objects right down to the microscopic scale, a scale at which the system cannot make spatial discriminations, rather than simply remaining neutral about invisibly microscopic spatial properties?

${ }^{9}$ I also recount and discuss this anecdote in Raleigh (2009), though in the service of a quite different philosophical point.

${ }^{10}$ See 151 of the $2^{\text {nd }}$ edition of Anscombe's An Introduction to Wittgenstein's Tractatus (1963/1959). Many thanks to Sofia Miguens for help tracking down this reference.
} 
In the past the following line of thought may have seemed correct:

(1) The way that the earth perceptually appears indicates (provides non-conclusive evidence) that the earth does not rotate.

(2) The Copernican theory tells us that the earth is rotating.

So, (3) What perceptual experience 'tells' us about the earth differs from what the Copernican theory tells us.

Someone defending the Copernican, rotating-earth theory might accept this line of thought. They might allow that perceptual appearances are misleading - the earth is not in fact the way that its appearance suggests. This would be to concede that appearances really do weigh against their theory to some extent, but that the evidence of appearances is not decisive. Wittgenstein's move in the story is to reject premise 1 . The way that the earth appears does not indicate (provide evidence) that the earth does not rotate - it is only a wrong- headed conception or background beliefs that leads us to infer non-rotation from the earth's appearance. We might sympathise with a subject who is ignorant of astronomy erroneously taking the appearance of the earth to support non-rotation and to weigh against rotation, but we now realise that this way that the earth + sky look is in fact accounted for and explained by the earth's rotation and so does not provide support for the non-rotation theory. Such a subject would not just be wrong about whether the earth rotates, they would also be wrong about the evidential bearing of the earth's appearance on this astronomical question - for they would fail to grasp that the way the earth+sky appear just is how a rotating planet does look to an observer on the surface of such a planet. How else should or could a rotating planet look to a human-sized observer located on its surface?

\section{Compare now:}

$\left(1^{*}\right)$ The way that the table perceptually appears indicates (provides non-conclusive evidence) that the table has certain properties - e.g. that it's matter entirely fills the space, 
that it is made of a gap-less homogeneous substance, that it has sharply defined boundaries.

$\left(2^{*}\right)$ Physics tells us that that the collection of micro-particles which compose the table does not have these properties.

So, $\left(3^{*}\right)$ What perceptual experience indicates about the nature of table is different to what physics tells us about the nature of the table.

I suggest that we can make a move parallel to Wittgenstein's and reject premise $1 *$. The way that the table perceptually appears in human experience does not indicate that it is homogenous or gap-less or has perfectly sharp boundaries right down to the microscopic level. That may be something that we foolishly infer or conceive in response to our experience. But the experience itself provides no such indication. Eddington, insofar as he is assuming that the manifest macroscopic appearance of the table is in conflict with what physics tells us about the table's micro-structure, would effectively be making the same move as Wittgenstein's pupil in the story. Again, and bearing in mind the analogy with seeing a distant sandy beach, we should ask a question parallel to Wittgenstein's: how else should a cloud of micro-particles look to a macroscopic observer whose visual system is bound to have natural limits on its resolution/acuity? Assuming that the table is, in fact, nothing over and above a cloud of micro-particles 'arranged table-wise', we should simply conclude that the way that the table in fact looks is the way that a swarm of micro-particles in fact looks (to a macroscopic observer with our kind of visual system).

To put this point in a slightly different way: we can read the student in the story as suggesting that for someone as yet undecided as to whether the earth rotates it would be reasonable to think: well, if the earth really does rotate we should expect it to look different to how it does in fact look. Wittgenstein, in the story, warns that us that when we think a little harder we realize that assuming the truth of the earth-rotating hypothesis one should then in fact expect the earth+sky to look just as it does in fact look. We may likewise be tempted to think that for someone undecided about the nature of the physical matter that composes the table, it would be reasonable to think: well, if the table is composed of a highly non-homogeneous cloud of particles that lacks sharply defined 
edges and boundaries, etc., then we should expect it to look different to how it in fact looks to us. But once we think a little harder and recall that the failures of homogeneity and deviations from sharply-defined-boundaries that physics alleges are supposed to take place at invisibly microscopic scales, then we come to realize that given the truth of our best scientific theories of physical matter we should not reasonably expect the table to look any other way.

Now, just as the appearance of the earth and sky may well have been what prompted people in the past to hold geo-centric views, I am not denying that the perceptual appearances of familiar everyday objects, such as tables, may well have prompted some people to believe that the material composing such objects is homogeneous and gapless and fully fills the space it occupies etc. Indeed, relative to all the faulty background theories/beliefs people had in pre-Copernican eras it may even have been rational for them to treat the appearance of the earth and sky as evidence for the geocentric/nonrotating theory. And so likewise, perhaps relative to enough erroneous background beliefs/theories, it could be rational (in this relative/subjective sense of rational) to treat the appearance of the table as providing evidence for the folk conception of matter as a homogenous substance etc. It could presumably be reasonable, relative to some set of wildly false background beliefs to take virtually anything to be evidence for virtually anything. What I am denying is that these perceptual appearances in themselves really do indicate or provide evidence for the faulty, folk conception. There is nothing intrinsically misleading about the appearance of the earth + sky. Once we abandon the erroneous background belief that the earth is a fixed point about which the rest of the heavenly bodies rotate, we come to realize that the appearance of the earth + sky is just as we should expect it to be. Likewise, my suggestion is that the appearance of the table does not really provide any indication or evidence in favour of the common-sense conception of substance. Once we abandon this naïve view of the nature of physical matter, we ought to come to realize that here also the appearance of the table is just as we should expect it to be, given the truth of our best scientific theories. 


\section{A potential worry}

A potential worry one might have about the sort of moral I have drawn from the Wittgenstein anecdote, is that it threatens to over-generalise and so to undermine the very distinction between illusory and non-illusory appearances.

Consider, as an example of a paradigmatically illusory appearance, the Müller-Lyer illusion - could we make a parallel suggestion here and say: 'well, how else should we expect equal length lines with Müller-Lyer arrow heads on to look, to humans with our kind of visual physiology? We might sympathise with people who erroneously take the appearance of the lines to indicate that they are different lengths, but now that we understand how the human visual system works, how else should we expect such equallength lines to look to normal human visual systems? That just is how Müller-Lyer lines do in fact look (to normal human visual systems)'.

And so then it might seem that we would start to lose our grip on the distinction between illusory and non-illusory appearances. If the Wittgenstein-story move were always legitimate, then the external physical scene/world could turn out to be any way whatever or have any fundamental physical nature whatsoever, and we could still simply respond: well, I guess that's how such a external physical state of affairs turns out to look/appear to normal human vision in such and such conditions ${ }^{11}$.

Let's assume that Wittgenstein's reply in the original story was making a cogent point that we want to hold onto, whereas, let's assume, the parallel sort of move with the Müller-Lyer would be illegitimate, or at least much less persuasive. The question then: is there some principled basis by which to vindicate Wittgenstein's move in the original

\footnotetext{
${ }^{11}$ It is perhaps worth noting that this may not necessarily be an unwelcome consequence. Chalmers (forthcoming) argues for a form of 'spatial functionalism' on which the content of spatial experience is, roughly: whatever physical property is the normal cause of this kind of experience. Chalmers comments: 'If spatial functionalism is correct... then systematic lifelong illusions about space are much more difficult to sustain. In particular, if we pick out spatial properties as the normal causes of spatial experiences, then situations in which spatial experiences are normally caused by properties other than the spatial properties they represent will be ruled out.' (Chalmers, forthcoming, 24)
} 
story, but rule out the parallel kind of moves in those cases, such as the Müller-Lyer, which we want to count as inherently misleading appearances?

One natural thought at this point might be to appeal to the notion of the representational content of experience in order to provide a criterion of when visual appearances are inherently illusory. For within the representational framework an experience will count as illusory if its content incorrectly represents the object of perception as being some way that it is not. So if we already, independently, had a theory about the (phenomenal) content of experience, which could tell us, in each of these situations, what the genuinely phenomenal content of the experience is (as opposed to what we are merely inclined to judge on the basis of an experience), then such a theory would allow us to classify all these experiences as being accurate or inaccurate, illusory or non-illusory. We might then get the result that: a normal, temporally extended experience of the earth+sky does not have inaccurate content that the earth is still but the sky is moving, whereas the MüllerLyer experience does have inaccurate content that the lines are unequal in length. Thus we might get a principled basis to vindicate Wittgenstein's move in the original story, but not the parallel moves in the other cases.

However, it is a hotly contested question what exactly the genuinely visual/phenomenal contents of visual experience are. For a start there is disagreement as to whether only 'low-level' properties (shape and colour, perhaps also depth and illumination) are represented $^{12}$, or whether 'higher-level' properties (such as natural kind properties, semantic properties, mental/emotional properties, affordances, etc.) are also represented $^{13}$. There is also disagreement about which specific kinds of spatial and colour properties are represented ${ }^{14}$. There is even disagreement as to whether familiar everyday objects figure in the content of experience at all ${ }^{15}$. And then there are familiar debates as to whether the content of experience is determined along externalist or internalist lines.

\footnotetext{
12 See e.g. Tye 1995, Dretske 1995, Price 2009, Brogaard 2013.

13 See e.g. Peacocke 1992, Siegel 2006, Bayne 2009, Nanay 2011.

${ }^{14}$ For debate about the specific kind of spatial properties represented in experience see: Casullo 1986, Cussins 1990, Peacocke 1992.

15 See Clark 2000.
} 
Moreover, it seems unlikely that these questions will be empirically settled any time soon. For even if we had some well-confirmed, widely accepted theory about the content of all the various sub-personal mechanisms in the visual system, we would still need a theory of how/when such sub-personal contents 'enter into' personal-level consciousness - which is something that cognitive science (or philosophy for that matter!) still seems a very long way from being able to deliver. It would be illegitimate then, in the present context, to simply assume that whatever the correct theory of the phenomenal content of visual experience turns out to be, it will vindicate Wittgenstein's move in the original story but not the parallel move for the Müller-Lyer (etc).

So instead of discussing the representational content of experience, I'll try to briefly sketch what I take to be the underlying reason why we feel that the move made in the original Wittgenstein story is legitimate, but that it would not be in the case of, say, the Müller-Lyer. I think the main relevant reason why we intuitively count the Müller-Lyer as an optical illusion, is that the appearance of the items in question is not predicted by our intuitive folk understanding of visual appearances. I take this sort of folk understanding to include a rough, implicit grasp of the relativity of visual appearances to perspective and to distance. We expect that a circular penny at an angle will look a certain way that we might describe as 'elliptical'. We expect things further away to take up less of the visual field and so, in a sense, 'look smaller'. We expect to see much less of the fine detail of some item when we observe it from a goodly distance away or in poor light etc.

The appearance of the earth and sky is in fact in accord with such a folk understanding of visual appearances - this is why Wittgenstein's rejoinder to his student in the original anecdote was a good one. We may have some initial temptation to think that a rotating earth should somehow look more 'spinny'! But actually, on reflection, we realise that it was wrong-headed to expect the earth + sky to look any other way, even by the standards of our folk/naïve theory of visual appearances. Whereas, the appearance of the MüllerLyer is not to be expected by the lights of our intuitive theory of visual appearances. In the case of these optical illusions we can specify some other way that we might 
reasonably expect the equal length lines to look, by the lights of our folk theory. We intuitively expect equal-length lines with Müller-Lyer arrow heads drawn on the end to look, so far as length is concerned, the same damn way that equal length lines without the arrow heads look! That is why, I take it, people are surprised when they first encounter the Müller-Lyer illusion and it is revealed that the lines are in fact of equal length. (And which is why, in turn, the Müller-Lyer illusion has been reproduced so often in books of 'optical illusions' that are meant to be fun to look at.)

Of course by the lights of our best scientific theory of human vision and visual appearance we should not have these expectations. But we count the Müller-Lyer - and other classic illusions like the Kanizsa triangle, or the Ebbinghaus circles, or Zöllner's diagonal lines, etc. - as optical illusions because they flout our folk expectations of how objects should look. And thus we would count it as quite rational, before we learn about the illusion, to treat the appearance of the Müller-Lyer lines as evidence that they are unequal in length. In contrast, we cannot specify some other way that we might reasonably expect a rotating planet whose surface we are located on to look, even by the lights of our folk/naive theory of visual appearances. And so it would not be rational to treat the appearance of the earth+sky as evidence favouring the non-rotating theory over the earth-rotating theory.

I have deliberately not said much about what exactly our intuitive/folk theory of visual appearances is committed to as this is, of course, ultimately an empirical matter. I would expect that some such expectations are probably relatively fixed/hard-wired - but there may be also be much that is learnt and culturally-dependent etc. E.g. perhaps a caveman would be amazed by photographs, television, realistic perspectival images etc., with no intuitive expectation that flat surfaces could have such an appearance of 3-d depth. But we moderns, exposed as we are from early infancy to endlessly many such images, have no inclination to treat these appearances/experiences as inherently misleading or illusory - we have absorbed the possibility that flat images can look this way into our intuitive/folk understanding of visual appearances. 
How does this folk/intuitive basis for categorising visual appearances as misleading or illusory relate to the more philosophical notion of accurate/inaccurate contents of experience? Well, clearly they would conflict in cases where either: (i) our folk theory does not predict that a scene/object should look this way, but in fact the content phenomenally encoded/embodied by the experience (that way of looking) is accurate, or (ii) our folk theory does predict that the scene/object should look this way, but in fact the phenomenal content is inaccurate. But notice, even supposing there are sometimes occasional cases of either of (i) or (ii), you still might think that our folk theory/grasp of visual appearances - i.e. how we expect objects/scenes to look in various circumstances is still imperfectly tracking the accurate/inaccurate content distinction. And so whether an experience fits/flouts our intuitive, folk theory of appearances could still be a reasonably good heuristic/guide for when it's phenomenal content is accurate/inaccurate ${ }^{16}$.

Now, when it comes to the fact that everyday objects are actually composed of exotic micro-particles, my suggestion is that it is part of our everyday folk conception of appearances that we will be visually insensitive to very tiny details. And so the fact that, when we look at the table, we cannot visually discriminate lots of microscopically tiny particles with lots of microscopically tiny spaces between them is to be expected, even by the lights of our folk naïve theory of visual appearances. For this folk theory includes the idea that below a certain scale, or from a certain distance away, features become invisible. That was the point of the comparison with the distant beach. Even if the perceiving subject had never encountered a beach before and knew nothing of sand, if they have a normal folk theory of visual appearances, then when they do eventually get right up close to the beach and discover that it is composed of lots of tiny grains of sand they will not, I suggest, be inclined to treat their previous experience of the beach from a distance as illusory. Likewise, I suggest, when we discover that the table and its matter is in fact composed of a swarm of tiny micro-particles with lots of space in between them, we may have some initial inclination to think that the way the table looks is illusory or deceptive. But once we reflect that the micro-particles and their spatial relations are

\footnotetext{
${ }^{16}$ Though of course if you already have a theory of visual content according to which we are constantly subject to systematic illusions, then our folk theory/grasp of expected visual appearances could not provide this kind of useful heuristic/guide.
} 
vastly smaller than anything we could reasonably expect to be able to discriminate by sight, we realise that we should not reasonably expect microscopic particles or the gaps in between them to show up in macroscopic shape appearances, even according to our naïve/everyday folk grasp of visual appearances ${ }^{17}$.

\section{Conclusion}

I've argued that any mistaken views that we 'folk' may naively harbor about the substantial, gap-less nature of physical matter cannot simply be read-off from the deliverances of our visual experiences. However, that leaves open that the nature of visual spatial experience may clash with our best physical theories in various other respects.

For example: you might think that the non-Euclidean, 'curved' nature of space is in tension with the apparently Euclidean nature of space in experience ${ }^{18}$. Or one might think that the relativity of shape to an observer's frame of reference, according to the Special Theory of Relativity, is in tension with our spatial phenomenology ${ }^{19}$. Or you might think that scientific theories according to which there are actually more than 3 spatial dimensions clashes with the 3-dimensional nature of our spatial experience.

It would then be an interesting question in each of these cases whether appealing to the indeterminacy of content, or to something like the Wittgenstein-story move, would be legitimate. E.g. to claim that: Experience represents space/shape as being approximately Euclidean, at everyday scales - and so there is not after all any clash with scientific theories which tell us that space is non-Euclidean but closely approximates a Euclidean 3-D space at our humdrum, everyday human scales. Or to claim something like: 'well,

\footnotetext{
${ }^{17}$ And if the line of thought in section 3 was correct, when we think in terms of the representational content of experience, nor should we reasonably take our normal visual experience of macroscopic objects to positively represent a lack of microscopic particles and gaps.

${ }^{18}$ Though in fact a number of philosophers and psychologist, going back at least to Thomas Reid, have denied that visual space is Euclidean - see Wagner 2006 for a summary of the psychological literature, see Van Cleve 2002, Meadows 2011, Masrour 2015 for philosophical discussions.

${ }^{19}$ See Chalmers (forthcoming).
} 
how should curved space appear? That is just how we should expect items in curved, non-Euclidean space to look at our human-sized scales, or relative to our frames of reference'. But those will have to be questions for other occasions ${ }^{20} \ldots$

\section{References}

- Anscombe, G. E. M. (1963/1959) An Introduction to Wittgenstein's Tractatus (2 $^{\text {nd }}$ Revised Edition), NY: Harper \& Row

- Bayne, T. (2009) "Perception and the reach of phenomenal content," Philosophical Quarterly, 59 (236): 385-404.

- Baysan, U. \& Wilson, J. (2017) 'Must Strong Emergence Collapse?' Philosophica 91: 49-104.

- Brogaard B. (2013) Do We Perceive Natural Kind Properties? Philosophical Studies 162 (1): $35-42$.

- Cambell, J \& Cassam, Q. (2014). Berkeley's Puzzle: What Does Experience Teach Us? OUP Oxford.

- Carrasco M. (2011). Visual attention: The past 25 years. Vision Research 51: 1484-1525.

- Casullo, A. (1986) "The Spatial Structure of Perceptual Space," Philosophy and Phenomenological Research, 46 (4): 665-71.

- Chalmers, D. (forthcoming) 'Three Puzzles About Spatial Experience', in A. Pautz and D. Stoljar (eds.), Themes from Ned Block, Cambridge, MA: MIT Press.

- Clark, A. (2000) A Theory of Sentience, Oxford: Oxford University Press.

- Cussins, A. (1990) "Content, Conceptual Content, and Nonconceptual Content," in Essays on Nonconceptual Content, Y. Gunther (ed.), Cambridge, MA: MIT Press, pp. 133-163.

- Cutter, B. (forthcoming) 'Indeterminate Perception and Color Relationism' Analysis.

- Dretske, F. (1995) Naturalizing the Mind, Cambridge, MA: MIT Press

- Eddington, A. (1928) The Nature of the Physical World. London, Dent.

- Eddington, A. (1939) Philosophy of Physical Science. Cambridge University Press.

- Esfeld, M. (2009). The modal nature of structures in ontic structural realism. International Studies in the Philosophy of Science, 23, 179-194.

- French, S., \& Ladyman, J. (2003). Remodelling structural realism: quantum physics and the metaphysics of structure. Synthese, 136, 31-56.

- Ganson T. \& Bronner B. (2013). Visual prominence and representationalism. Philosophical Studies 164 (2): 405-418.

${ }^{20}$ Earlier versions of this paper were presented at events at V. U. Amsterdam, Ben-Gurion University, University of Warwick, H.S.E. Moscow, Ruhr University Bochum, University of Porto, University of Antwerp and the United Arab Emirates University. I am grateful to the audiences on all those occasions for their feedback. Many thanks in particular to Alma Barner, Ori Beck, Silver Bronzo, Peter Brössel, José Pedro Correia, Luca Corti, Alison Fernandes, Laura Gow, Jonathan Knowles, Kevin Lande, Raamy Majeed, Tom McClelland, William McDonald, Phillip Meadows, Sofia Miguens, Bence Nanay, Jim Pryor, Susanna Siegel, Charles Travis, Dan Williams and Nick Wiltsher for their comments and criticisms. Finally, thanks also to an anonymous referee for this journal for her/his helpful report. 
- Gillet, C. (2002) 'Strong Emergence as a Defense of Non-Reductive Physicalism' Principia: An International Journal of Epistemology 6 (1): 87-120

- Gillet, C (2003) 'The Metaphysics of Realization, Multiple Realizability, and the Special Sciences" The Journal of Philosophy, 100: 591-603.

- Gobell J. \& Carrasco M. (2005). Attention alters the appearance of spatial frequency and gap size. Psychological Science 16 (8): 644-651.

- Masrour, F. (2015) "The Geometry of Visual Space and the Nature of Visual Experience", Philosophical Studies 172 (7): 1813-1832.

- Maxwell, G. (1970). Structural realism and the meaning of theoretical terms. In S. Winokur \& M. Radner (Eds.), Analyses of theories, and methods of physics and psychology, Minneapolis: University of Minnesota Press.

- Meadows, P. (2011) 'Contemporary Arguments for a Geometry of Visual Experience', European Journal of Philosophy 19 (3): 408-430.

- Nanay B. (2010) 'Attention and perceptual content', Analysis 70: 263-270.

- Nanay, B. (2011) “Do we see apples as edible?” Pacific Philosophical Quarterly, 92 (3): $305-322$

- Nanay, B. (2018) 'Blur and Perceptual Content', Analysis 78 (2): 254-260.

- Peacocke (1992) 'Scenarios, Concepts, and Perception', in Tim Crane (ed.), The Contents of Experience, Cambridge University Press.

- Pereboom, D. (2002) 'Robust Non-Reductive Materialism' Journal of Philosophy 99: 499-531.

- Price, R. (2009) “Aspect-Switching and Visual Phenomenal Character", Philosophical Quarterly 59 (236): 508-518.

- Raleigh, T. (2009) "Understanding How Experience 'Seems", European Journal of Analytic Philosophy, 5(2): 67-78.

- Russell, B. (1927) The analysis of matter, London: George Allen \& Unwin.

- Sellars, W. (1962) "Philosophy and the Scientific Image of Man," in Frontiers of Science and Philosophy, Robert Colodny (ed.) Pittsburgh, PA: University of Pittsburgh Press.

- Siegel, S. (2006) "Which Properties are Represented in Perception?" in In Perceptual Experience, T. Gendler Szabo and J. Hawthorne (eds.), Oxford: Oxford University Press, 481-503.

- Stazicker J. (2011) 'Attention, visual consciousness and indeterminacy', Mind \& Language 26 (2): 156-184.

- Tye, M. (1995) Ten Problems of Consciousness, Cambridge, MA: MIT Press

- Van Cleve, J. (2002) “Thomas Reid's Geometry of Visibles”, The Philosophical Review, $111,373-416$.

- Wagner, M. (2006) The Geometries of Visual Space, London: Erlbaum

- Wilson, J. (2010) 'Non-Reductive Physicalism and Degrees of Freedom' British Journal for Philosophy of Science 61 (2): 279-311.

- Wilson, J. (2011) "Non-Reductive Realization and the Powers-Based Subset Strategy", The Monist 94:121-154.

- Wilson, J. (2015) "Metaphysical Emergence: Weak and Strong”. In: T. Bigaj and C. Wuthrich (eds.), Metaphysics in Contemporary Physics Poznan Studies in the Philosophy of the Sciences and the Humanities, Leiden: Brill: 345-402.

- Worrall, J. (1989). Structural realism: The best of both worlds? In D. Papineau (Ed.), The philosophy of science. Oxford: Oxford University Press.

- Yeshurun Y. \& Carrasco M. (2008). The effects of transient attention on spatial resolution and the size of the attentional cue. Perception \& Psychophysics 70 (1): 104113. 